\title{
Thromboembolic episodes related to atrial arrhythmias in adults with transposition of great arteries
}

\author{
Darryl Wan ${ }^{1}$, Clara Tsui ${ }^{1}$, Jasmine Grewall ${ }^{1}$, Marla Kiess ${ }^{1}$, Amanda Barlow', Derek Human ${ }^{1}$, Andrew Krahn ${ }^{1}$ \\ and Santabhanu Chakrabarti ${ }^{1,2^{*}}$
}

\begin{abstract}
Background: Atrial arrhythmias (AA) are common in adults with congenital heart disease (ACHD). Although Intra-atrial Reentrant Tachycardia (IART) is well described in ACHD, Atrial Fibrillation (AF) is uncommon, but increasingly recognized. Patients with Transposition of the Great Arteries (TGA) and congenitally corrected-TGA (CC-TGA) have a high burden of AA at a relatively young age. However, long-term data of AA and associated thromboembolic risk are lacking in these patients. The prevalence, associated clinical factors, and complications of AA in a longitudinal TGA cohort was studied.

Methods: A retrospective cohort study of all TGA patients from a single tertiary care centre was conducted. Data regarding documented atrial arrhythmias, thromboembolic events, and factors associated with thromboembolism were extracted and analyzed. Mean values and standard deviations were calculated for normally distributed continuous variables. When frequencies and means were compared, the chi-squared test and student t-test were used, respectively.

Results: One-hundred twenty-five patients with TGA (76 TGA, 49 CC-TGA) were followed for a mean of $20.8 \pm 13.2$ years. AF was confirmed in 20\% $(n=25)$ and there were $5(20 \%)$ thromboembolic complications within the AF population. AF was associated with an annual thromboembolic event rate of $2.7 \% / y e a r$ (stroke/transient ischemic attack 1.7\%, systemic embolism 1.0\%).

Conclusion: AF is relatively common in the TGA ACHD population in long-term follow up. Although annual risk of thromboembolism is low in this young group of patients, life-time cumulative risk is potentially high. TGA patients should be screened actively for AF and appropriate anticoagulation therapy initiated. It is unclear if established risk prediction scores in other non-valvular AF populations may be applicable to this cohort.
\end{abstract}

Keywords: Atrial fibrillation, Congenital heart disease, Atrial arrhythmia

\section{Background}

Atrial fibrillation (AF) is the most common atrial arrhythmia in the general population, estimated to occur at a prevalence of $0.95 \%$ [1]. Although AF is uncommon in adults under the age of 55 , it is increasingly recognized to occur at a younger age in adults with congenital heart disease (ACHD).

\footnotetext{
* Correspondence: SChakrabarti@providencehealth.bc.ca

${ }^{1}$ Division of Cardiology, University of British Columbia, Vancouver, Canada ${ }^{2}$ Heart Rhythm Services, Department of Medicine, Division of Cardiology, St. Paul's Hospital-University of British Columbia, Suite 211-1033 Davie St, Vancouver, BC V6E 1M7, Canada
}

(c) The Author(s). 2017 Open Access This article is distributed under the terms of the Creative Commons Attribution 4.0 International License (http://creativecommons.org/licenses/by/4.0/), which permits unrestricted use, distribution, and reproduction in any medium, provided you give appropriate credit to the original author(s) and the source, provide a link to the Creative Commons license, and indicate if changes were made. The Creative Commons Public Domain Dedication waiver (http://creativecommons.org/publicdomain/zero/1.0/) applies to the data made available in this article, unless otherwise stated. Tachycardia: IART, Atrial Flutter: AFL, Focal Atrial Tachycardia: FAT, and AF) are a common sequelae in the ACHD population, accounting for significant morbidity and mortality associated with poor quality of life, increased thromboembolic risk, and sudden death [2-4]. The majority of cases with atrial arrhythmias involve patients who have undergone prior reparative cardiac surgery [5]. AF is a growing concern and has been shown to have important associations with stroke and heart failure, especially with increasing age [6-8]. In addition to the known thromboembolic risk associated 
with AF, ACHD patients face a host of unique issues and complications related to their specific cardiac lesions [2].

We investigated the prevalence and risk factors associated with development of $\mathrm{AF}$ and thromboembolic risk associated with AF, AFL or IART in a consecutive observational cohort of CC-TGA and post-atrial switch TGA patients.

\section{Methods}

Our Adult Congenital Heart Disease Clinic is the designated single advanced care provider for all provincial patients with ACHD, in a single payer public health care system situated in Vancouver, British Columbia, Canada. This study was a single centre, retrospective observational cohort of all adults $\geq 18$ years with TGA (TGA with atrial switch and CC-TGA) seen in the Adult Congenital Heart Disease Clinic. Examination of case charts was conducted based on data extracted from the clinic database. Information recorded included basic demographic information, cardiac procedures, arrhythmia on electrocardiogram (rhythm strip or standard 12-lead ECG) thromboembolic events, co-morbidities and concurrent medical treatment.

One hundred twenty five TGA patients were identified from the ACHD database. Two patients were excluded due to incomplete follow up data after migration out of province. The thromboembolic outcomes were defined as clinically adjudicated with imaging confirmation when available. Arrhythmia diagnosis was as adjudicated by the treating cardiologist with confirmation from ECG/ Holter and electrophysiology studies (Fig. 1).

Descriptive statistics for nominal data were expressed in absolute numbers and percentages. Mean values and SDs were calculated for normally distributed continuous variables. When frequencies and means were compared, the chi-squared test and student t-test were used, respectively. For all analyses, two-tailed $P$-values $<0.05$ were considered statistically significant. Thromboembolic risk prediction was modeled using the CHADS-VASc risk factors, but specific scores were not calculated. Institutional Research and Ethics Board approval was obtained prior to initiation of the study.

\section{Results}

One hundred twenty five patients with TGA (TGA with atrial switch and CC-TGA) were identified and data from 123 patients were used for analysis. Seventy-five subjects (61\%) had TGA and 48 had CC-TGA (39\%). The mean age of the TGA patients was $34.5( \pm 7.6)$ years, while the average age of the CC-TGA patients was 45.4 $( \pm 18.3)$ yrs. Males were predominant in the study population, accounting for 70/123 (57\%). The mean follow up duration was $20.8( \pm 13.2)$ years (Table 1$)$.

Atrial Fibrillation was identified in 25 patients (20.3\%), in whom 20 had paroxysmal AF and 5 had permanent AF at last contact. The onset of AF was first documented at age $37.2 \pm 11.2$ years, with latest follow-up at $46.8 \pm 12.5$ years. The majority were males $(17 / 25,68 \%)$. AF was associated with previous occurrence of IART, ventricular tachycardia and requirement of implantable cardiac defibrillator $(p=0.01)$, but not associated with age, sex, previous heart surgeries, heart failure, NYHA functional class, or requirement of pacemaker.

Five subjects had cerebrovascular accidents after the onset of AF (stroke: $n=3$, TIA: $n=2$ ). There were 1.7 CVA events per 100 patient years of follow-up after onset of AF. Systemic thromboembolism $(n=3)$ risk was $1 \%$ per year after onset of AF.

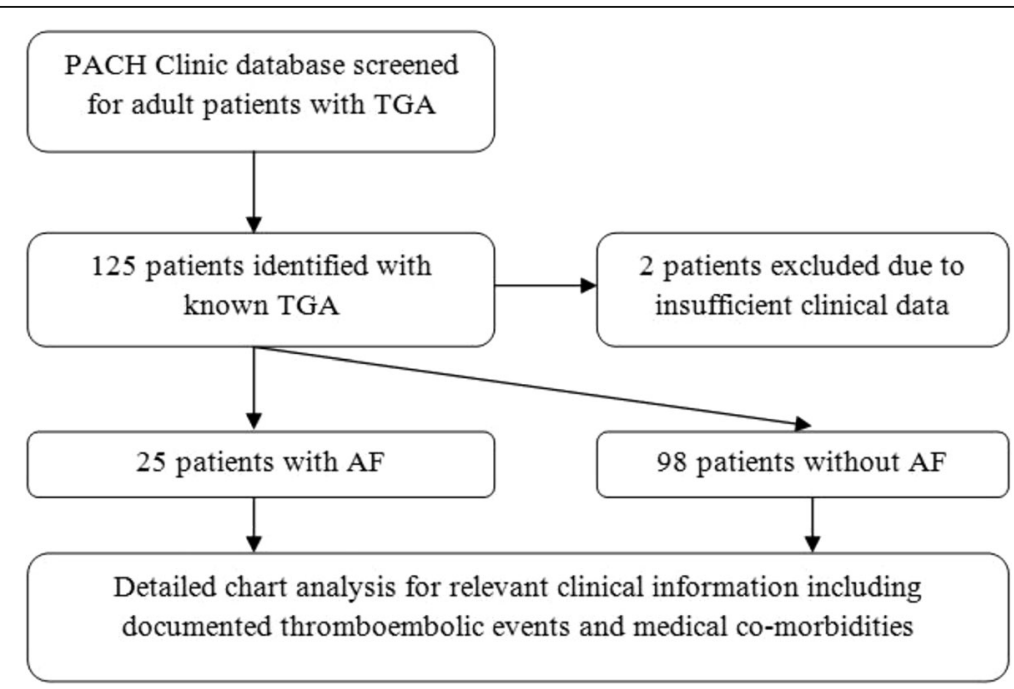

Fig. 1 Flow diagram showing selection of suitable patients for inclusion in study 
Table 1 Demographic information for patients included in study

\begin{tabular}{|c|c|c|}
\hline & TGA & CC-TGA \\
\hline Total number & 75 & 48 \\
\hline Average age & $34.5( \pm 7.6)$ & $45.4( \pm 18.3)$ \\
\hline Male & $40(53 \%)$ & $30(62 \%)$ \\
\hline \multicolumn{3}{|l|}{ Surgeries } \\
\hline Mustard procedure & $64(85)$ & 0 \\
\hline Senning procedure & $11(15)$ & 0 \\
\hline \multicolumn{3}{|l|}{ Devices } \\
\hline Pacemaker & $20(26 \%)$ & $20(41 \%)$ \\
\hline$I C D$ & $5(6 \%)$ & $5(10 \%)$ \\
\hline Biventricular pacing & $1(1.3 \%)$ & 0 \\
\hline Mechanical valve & 0 & $5(10 \%)$ \\
\hline \multicolumn{3}{|l|}{ Medications } \\
\hline Lasix & $3(4 \%)$ & $11(23 \%)$ \\
\hline Beta blocker & $22(29 \%)$ & $17(35 \%)$ \\
\hline ACE inhibitor & $20(27 \%)$ & $25(52 \%)$ \\
\hline Digoxin & $1(1.3 \%)$ & $7(15 \%)$ \\
\hline Warfarin & $7(9.3 \%)$ & $13(27 \%)$ \\
\hline ASA & $9(12 \%)$ & $11(23 \%)$ \\
\hline \multicolumn{3}{|c|}{ Systemic RV systolic function } \\
\hline Mild dysfunction & $41(55 \%)$ & $26(54 \%)$ \\
\hline Moderate dysfunction & $24(32 \%)$ & $9(19 \%)$ \\
\hline Severe dysfunction & $5(7 \%)$ & $8(17 \%)$ \\
\hline
\end{tabular}

\section{Stroke and transient ischemic attack (TIA)}

Thirteen patients with AF had stroke/TIA. However, six occurred during childhood. These were associated with surgery $(n=3)$, deemed idiopathic $(n=2)$ or due to possible intrauterine insult $(n=1)$. Hence, these were excluded from further analysis. In six of the remaining seven patients $(7 / 123,5.6 \%)$, TIA/ stroke was confirmed on brain CT or MRI. The remaining patient had clinical TIA without radiological confirmation. The average age of presentation was 38.1 (range 25-50 years). The details of atrial arrhythmias and thromboembolic findings are described in Table 2 .

There was a significant preponderance of male sex in the thromboembolic event group $(6 / 7, p<0.05)$ and presence of $\operatorname{AF}(5 / 7, p=0.038)$. Most subjects $(4 / 5,80 \%)$ had paroxysmal AF, while only one subject had persistent AF. No patient with IART had stroke. TGA patients with heart failure requiring diuretic therapy were also more likely to have stroke/TIA than those who were not $(p=0.03)$. Incidence of diabetes, hypertension and peripheral vascular disease were not significantly different in the stroke/TIA population versus the rest of the study population.
Table 2 Summary of all thromboembolic events in TGA and CC-TGA cohorts

\begin{tabular}{|c|c|c|}
\hline & TGA & CC-TGA \\
\hline $\begin{array}{l}\text { Atrial fibrillation } \\
\text { paroxysmal }\end{array}$ & $\begin{array}{l}10 \text { patients (13\%) } \\
\text { TIA: } 0 \\
\text { Stroke: } 6 \\
\text { - } 1 \text { peri-operative } \\
\text { Mustard } \\
\text { - } 1 \text { complication } \\
\text { post-op Mustard } \\
\text { Other: } 1 \text { renal infarct } \\
\text { Heart failure: } 1\end{array}$ & $\begin{array}{l}10 \text { patients }(21 \%) \\
\text { TIA: } 2 \\
\text { Stroke: } 1 \\
\quad-1 \text { during VSD repair } \\
\text { Other: } \\
1 \text { bilateral PE with infarction } \\
\text { Heart failure: } 1\end{array}$ \\
\hline $\begin{array}{l}\text { Atrial fibrillation } \\
\text { persistent }\end{array}$ & $\begin{array}{l}2 \text { patients } \\
\text { TIA: } 0 \\
\text { Stroke: } 0\end{array}$ & $\begin{array}{l}3 \text { patients } \\
\text { TIA: } 1 \\
\text { Stroke } 1 \\
\text { - Stroke and TIA in the same } \\
\quad \text { patient } \\
\text { Heart failure: } 1\end{array}$ \\
\hline $\begin{array}{l}\text { Atrial flutter } \\
\text { paroxysmal }\end{array}$ & $\begin{array}{l}15 \text { ( } 20 \%) \\
\text { TIA: } 0 \\
\text { Stroke: } 2 \\
\quad-1 \text { peri-operative } \\
\quad \text { Mustard } \\
\text { Other: } 1 \text { femoral artery } \\
\text { claudication }\end{array}$ & $\begin{array}{l}4(8 \%) \\
\text { TIA: } 0 \\
\text { Stroke: } 0 \\
\text { Other: } 1 \text { thrombosed } \\
\text { prosthetic AV and left popliteal } \\
\text { thrombosis in same patient }\end{array}$ \\
\hline $\begin{array}{l}\text { Atrial flutter } \\
\text { persistent }\end{array}$ & $\begin{array}{l}1 \\
\text { No thrombosis }\end{array}$ & $\begin{array}{l}1 \\
\text { No thrombosis }\end{array}$ \\
\hline $\begin{array}{l}\text { Ectopic atrial } \\
\text { tachycardia }\end{array}$ & 16(21\%) & $6(12.5 \%)$ \\
\hline AVRT/AVNRT & 1 & 2 \\
\hline
\end{tabular}

\section{Systemic thromboembolism}

In this group, apart from the cerebral thromboembolic episodes, three other subjects had systemic embolic complications $(3 / 123,2.4 \%)$, two had AF, and the other had IART.

One male patient with TGA and AF (documented by pacemaker electrogram) had a renal infarction at age 24 years but no CVA. Another 26-year-old with paroxysmal AFL developed popliteal artery thrombosis on a background of a history of mechanical aortic valve thrombus. The third patient was a 59-year-old male with CC-TGA and paroxysmal AF who had acute coronary syndrome from a presumed coronary embolism but normal coronary angiogram; he had multiple strokes 2 years later. Only one patient with thromboembolism had a baffle leak.

\section{Relationship between AF and IART/FAT}

Fourteen subjects with AF (14/20, 70\%) had previous IART that was documented by ECG or Holter. This is significantly higher than the ones who did not have AF (23/103, 22.3\%, $p<0.01)$.

Thirty seven patients $(37 / 123,30 \%)$ of the group had documented IART while $13 \%(n=22)$ patients had FAT. Six AF $(24 \%, 6 / 25)$ patients had documented FAT before developing AF in follow up. 


\section{Follow up}

The average follow up duration was $20.6 \pm 13.2$ years. There were seven deaths (5.6\%) One patient underwent cardiac transplant. Three patients in the AF group died (versus 4 in the non-AF group, $p=0.14$ ).

\section{Discussion}

This study reports the factors associated with AF and its complications in TGA with atrial switch and CC-TGA. Although the sample size is small, the relatively long follow up in a single tertiary care facility provides some meaningful insight into the situation. In our small cohort, AF was found in $20 \%$ of patients and was associated with a $2.7 \%$ annual thromboembolic event rate.

In the general population, AF is an established risk factor for thromboembolic stroke [7], significant morbidity and a $40-90 \%$ overall increase in mortality during longterm follow up $[6,8,9]$. While there may be similarities in AF affecting the general and ACHD population, these groups are inherently different in their co-morbidities, arrhythmia substrate, and presentation. With technological advances in arrhythmia detection, the true prevalence of atrial arrhythmias may be underestimated by this study. In addition to occurring at higher rates, AF also seems to have presented at a much younger age in our cohort. This is consistent with other studies showing relatively young age at development of AF in patients with ACHD [10]. Risk stratification systems such as $\mathrm{CHADS}_{2}$ [11] and CHADS-VASc [12] have been validated for use in non-valvular AF in the general population, but may not apply to ACHD.

It is very challenging to aggregate all ACHD into a single pathophysiological process in order to understand AF meaningfully. Therefore, we chose the TGA group as these patients have similar physiology with regards to susceptibility from atrial arrhythmia substrate and significant systemic ventricular dysfunction. The TGA patients who underwent atrial switch procedure are now in their third and fourth decades of life [2]. These patients are also experiencing the complications associated with systemic right ventricular dysfunction and are uniquely positioned as a study population in this regard.

The atrial switch procedure for TGA in the 1960s dramatically improved survival in that group [13-15]. However, long-term follow up care revealed growing problems in this population including systemic ventricular failure, valve regurgitation, and significant late arrhythmias [16-18]. In 2000, Oechslin et al. [16] described late atrial flutter or atrial fibrillation as a result of systemic ventricular dilatation and dysfunction, contributing as risk factors for death. Furthermore, Gatzoulis et al. [17] reported that sustained atrial flutter/fibrillation was found in $19.6 \%$ of their 51 adult TGA patients post-Mustard procedure.
In TGA, extensive atrial scar substrate may potentially lead to IART/FAT but it is unclear how this may progress to AF. Atrial dilatation may be a factor in CC-TGA but there is sparse evidence to validate this as a clinical risk. Furthermore, this is unlikely in TGA post-atrial switch procedure due to relatively poor distensibility of the baffle anatomy. AF was diagnosed in $20 \%$ of these patients. There were significant overlaps, but in the clinical context, it may be very challenging to differentiate between IART and FAT without intracardiac electrophysiological manoeuvres, especially with suboptimal P-waves on surface electrograms. The prevalence of AF in our study population is similar to previous experience with TGA but higher than the 11 to $15 \%$ prevalence of atrial arrhythmia in the general CHD population [19-21].

IART is well described in TGA but the significant risk of developing AF in the long term has not been reported previously. Due the high prevalence of AF in the TGA group, routine care should include active screening for atrial arrhythmias in this group of patients. By beginning early surveillance and active screening, prophylactic therapy can be initiated to reduce TE risk.

The risk of developing AF is high in AFL patients and therefore active monitoring is required.

The incidence of stroke is approximately $1 \%$ in the general population, increasing to up to $8 \%$ in the elderly [1]. Cerebrovascular accidents (CVA) are also responsible for a major contribution to morbidity in the young $\mathrm{CHD}$ population, despite the absence of traditional cardiovascular risk factors. A 2010 study by Hoffmann et al. demonstrated 10 to 100 times increased risk of CVA in the CHD population when compared to aged matched healthy controls in the general population [22].

Our data suggests an $8 \%$ prevalence of thromboembolic events in long term follow up, excluding pediatric/periprocedural events. This is currently under-recognized and likely to worsen with further follow up. The EuroHeart study showed a $6 \%$ prevalence of CVA but it is unclear if peri-procedural or previous events had been excluded [21].

Our data also demonstrates that males had significantly more thromboembolic episodes in the non-valvular AF population. The incidence of diabetes, hypertension and peripheral vascular disease is quite small in this young population. There was no association with diabetes, hypertension or peripheral vascular disease in our study, but in view of very limited numbers, the significance of this is uncertain. Heart failure predisposed to thromboembolic episodes risk in our group of patients. The median $\mathrm{CHADS}_{2}$ score in this population was 0 , and hence not predictive of thromboembolic risk.

With continued follow up, this group of patients with TGA in adulthood will continue to experience worsening of late complications and place a growing burden on existing limited healthcare resources [19]. Even though 
stroke/TIAs are relatively rare, they often leave sequelae which may add significantly to the disease burden in the ACHD population. The risk of thromboembolic episodes in our study may seem low. However, in this population with a relatively young mean age of 38 years at last follow-up, this figure is significantly higher than in an otherwise healthy general population.

\section{Limitations}

This study has several limitations, mostly from those associated with any retrospective analysis spanning over decades. The end points are clinical and may have been underestimated. For example, TIA or other embolic events cannot be excluded, as minor episodes may be overlooked by the patients, not be recorded by caregivers, or captured in a different hospital. However, our centre is the only tertiary centre in our province and has dependable follow up including regular telephone interviews with the Clinic Nursing team. Outcome definitions may have varied between the clinicians but this is unlikely, considering this is a single centre.

We acknowledge that the post-atrial switch procedure TGA and CC-TGA clinical profiles are different but they were included together because of the systemic RV which has high risk of systolic dysfunction and is a known risk factor for stroke in the non valvular AF population. We have therefore presented the data separately in these 2 groups.

In view of the small number of end points, meaningful prediction scores or trends using logistic regression were not possible and points towards the need for multicentre collaborative research in the future to have further insight into this problem. Alternatively, a central database for ACHD patients would be a useful adjunct to provide adequate numbers for meaningful statistical analysis and risk prediction.

Clinical parameters such as systemic ventricular ejection fraction, atrioventricular valvular regurgitation, and medications are dynamic and very likely to change over long term follow up in complex ACHD patients, hence those variables have not been included in data analysis. Moreover, the event rates for $\mathrm{AF}$ and thromboembolic complications are low, which precludes prediction of any solid risk scoring system. This emphasizes the crucial need for prospective data collection from multiple centres in the future to address these questions more effectively.

Finally, our findings may not be generalized to the ACHD cohort as a whole because comorbidities such as intracardiac shunt, erythrocytosis, cyanosis or mechanical valves independently affect stroke and thromboembolic risk.

\section{Conclusion}

AF is common in the TGA (TGA post atrial switch and CC-TGA) ACHD population in long term follow up. AF starts at a relatively young age and is often preceded by other atrial arrhythmias (IART/FAT). AF is associated with a risk of thromboembolic stroke (annual risk 1.7\%) and systemic thromboembolism (annual risk 1\%) totalling an overall $2.7 \%$ risk annually after onset of AF. Male sex and heart failure requiring diuretic use were associated with increased incidence of stroke/TIA.

TGA patients with non-AF atrial arrhythmias should be screened actively for AF and treated accordingly. Further multicentre, prospective studies are required for CVA and TE risk stratification in ACHD patients.

\section{Abbreviations \\ ACHD: Adults with congenital heart disease; AF: Atrial fibrillation; AFL: Atrial flutter; CC-TGA: Congenitally corrected transposition of the great arteries; CVA: Cerebrovascular accident; FAT: Focal atrial tachycardia; IART: Intra-atrial re-entrant tachycardia; RV: Right ventricle; TE: Thromboembolism; \\ TGA: Transposition of the great arteries; TIA: Transient ischemic attack}

Acknowledgements

Not applicable

Funding

No funding was provided.

Availability of data and materials

Not applicable

Authors' contributions

All authors contributed equally to the creation of this manuscript. DW: Data collection, drafting article. CT: Critical revision of article. JG: Critical revision of article. MK: Critical revision of article. AB: Critical revision of article. DH: Critical revision of article. AK: Critical revision of article. SC: Concept/design, data analysis/interpretation, approval of article. All authors read and approved the final manuscript.

Ethics approval and consent to participate

Retrospective patient chart data was used for this study. Institutional Research and Ethics Board approval was obtained prior to initiation of the study.

Consent for publication

Not applicable

Competing interests

The authors declare that they have no competing interests.

\section{Publisher's Note}

Springer Nature remains neutral with regard to jurisdictional claims in published maps and institutional affiliations.

Received: 22 June 2016 Accepted: 21 July 2017

Published online: 07 August 2017

References

1. Go AS, Hylek EM, Phillips KA, Henault LE, Selby JV, Singer DE. Prevalence of diagnosed Atrial fibrillation in adults: National Implications for rhythm management and stroke prevention: the AnTicoagulation and risk factors in Atrial fibrillation (ATRIA) study. JAMA. 2001;285:2370-5.

2. Warnes C a, Williams RG, Bashore TM, et al. ACC/AHA 2008 guidelines for the management of adults with congenital heart disease: a report of the American College of Cardiology/American Heart Association Task Force on Practice Guidelines (Writing Committee to Develop Guidelines on the Management of A. J. Am. Coll. Cardiol. [Internet] American College of 
Cardiology Foundation. 2008;52:e143-263. [cited 2014 Jan 21] Available from: http://www.ncbi.nlm.nih.gov/pubmed/19038677.

3. Yap S-C, Harris L, Chauhan VS, Oechslin EN, Silversides CK. Identifying high risk in adults with congenital heart disease and atrial arrhythmias. Am J Cardiol. 2011;108:723-8. [Internet] Elsevier Inc., [cited 2014 Mar 18]; Available from: http://www.ncbinlm.nih.gov/pubmed/21684512.

4. Khairy P, Van Hare GF, Balaji S, et al. PACES/HRS expert consensus statement on the recognition and Management of Arrhythmias in adult congenital heart disease. Heart Rhythm. 2014;11:e102-65. [Internet] Elsevier. Available from: http://linkinghub.elsevier.com/retrieve/pii/ S154752711400513X.

5. Kirsh JA, Walsh EP, Triedman JK. Prevalence of and risk factors for Atrial fibrillation and intra-Atrial reentrant tachycardia among patients with congenital heart disease. Am J Cardiol. 2002;90:338-40.

6. Benjamin EJ, Wolf $\mathrm{P}$ a., D'Agostino RB, Silbershatz H, Kannel WB, Levy D. Impact of Atrial fibrillation on the risk of death : the Framingham heart study. Circulation 1998:98:946-52. [Internet] [cited 2014 Jan 21] Available from: http://circ.ahajournals.org/cgi/doi/10.1161/01.CIR.98.10.946.

7. Wolf $\mathrm{P}$ a., D'Agostino RB, Belanger a. J, Kannel WB. Probability of stroke: a risk profile from the Framingham study. Stroke. 1991;22:312-8. [Internet] [cited 2014 Jan 20]. Available from: http://stroke.ahajournals.org/cgi/doi/10, 1161/01.STR.22.3.312

8. Stewart S, Hart CL, Hole DJ, Mcmurray JJV. A population-based study of the long-term risks associated with Atrial Fibrillation : 20-year follow-up of the Renfrew/paisley study. Am J Med. 2002;113:359-64.

9. Camm a J, Kirchhof P, Lip GYH, et al. Guidelines for the Management of Atrial Fibrillation: the task force for the management of Atrial fibrillation of the European Society of Cardiology (ESC). Eur Heart J. 2010;31:2369-429. [Internet] [cited 2014 Jan 21]; . Available from: http://www.ncbi.nlm.nih.gov/ pubmed/20802247.

10. Teuwen CP, Ramdjan TTTK, Götte M, et al. Time course of Atrial fibrillation in patients with congenital heart defects. Circ Arrhythm Electrophysiol. 2015;8: 1065-72. [Internet] Available from: http://circep.ahajournals.org/lookup/doi/ 10.1161/CIRCEP.115.003272.

11. Skanes AC, Healey JS, Cairns J a, et al. Focused 2012 update of the Canadian cardiovascular society atrial fibrillation quidelines: recommendations for stroke prevention and rate/rhythm control. Can J Cardiol. 2012;28:125-36. [Internet] Elsevier Inc. [cited 2014 Jan 23] Available from: http://www.ncbi.nlm.nih.gov/pubmed/22433576.

12. Lane D a, Lip GYH. Use of the CHA(2)DS(2)-VASC and HAS-BLED scores to aid decision making for thromboprophylaxis in nonvalvular atrial fibrillation. Circulation 2012;126:860-5. [Internet] [cited 2014 Feb 2] Available from: http://www.ncbi.nlm.nih.gov/pubmed/22891166.

13. Senning A. Surgical correction of transposition of the great vessels. Surgery. 1959:45:966-80

14. Mustard W, Chute A, Keith J, Sirek A, Rowe R, Vlad P. A surgical approach to transposition of the great vessels with extracorporeal circuit. Surgery. 1954; 36:31-51.

15. Mustard W. Successful two-stage correction of transposition of the great vessela. Surgery. 1964;55:469-72.

16. Oechslin E, Jenni R. 40 years after the first atrial switch procedure in patients with transposition of the great arteries: long-term results in Toronto and Zurich. Thorac Cardiovasc Surg. 2000; 48:233-7. [Internet] Available from: http://www.ncbi.nlm.nih.gov/pubmed/11005599.

17. Gatzoulis M a, Walters J, McLaughlin PR, Merchant N, Webb GD, Liu P. Late arrhythmia in adults with the mustard procedure for transposition of great arteries: a surrogate marker for right ventricular dysfunction? Heart . 2000; 84:409-15. [Internet] Available from: http://www.pubmedcentral.nih.gov/ articlerender.fcgi?artid=1729461\&tool=pmcentrez\&rendertype =abstract.

18. Gelatt M, Hamilton RM, McCrindle BW, et al. Arrhythmia and mortality after the mustard procedure: a 30-year single-center experience. J Am Coll Cardiol. 1997;29:194-201. [Internet] Available from: http://www.ncbi.nlm.nih. gov/pubmed/8996314

19. Bouchardy J, Therrien J, Pilote $L$, et al. Atrial arrhythmias in adults with congenital heart disease. Circulation. 2009;120:1679-86. [Internet] [cited 2014 Feb 8] Available from: http://www.ncbi.nlm.nih.gov/pubmed/ 19822808.

20. Bernier M, Marelli AJ, Pilote L, et al. Atrial arrhythmias in adult patients with right- versus left-sided congenital heart disease anomalies. Am J Cardiol. 2010:106:547-51. [Internet] Elsevier Inc. [cited 2014 Feb 8] Available from: http://www.ncbi.nlm.nih.gov/pubmed/20691314.
21. Engelfriet $P$, Boersma $E$, Oechslin $E$, et al. The spectrum of adult congenital heart disease in Europe: morbidity and mortality in a 5 year follow-up period. The euro heart survey on adult congenital heart disease. Eur Heart J. 2005;26:2325-33. [Internet] [cited 2014 Mar 18] Available from: http://www. ncbi.nlm.nih.gov/pubmed/15996978.

22. Hoffmann a, Chockalingam P, Balint OH, et al. Cerebrovascular accidents in adult patients with congenital heart disease. Heart. 2010;96:1223-26. [Internet] [cited 2014 Feb 8] Available from: http://www.ncbi.nlm.nih.gov/ pubmed/20639238.

\section{Submit your next manuscript to BioMed Central and we will help you at every step:}

- We accept pre-submission inquiries

- Our selector tool helps you to find the most relevant journal

- We provide round the clock customer support

- Convenient online submission

- Thorough peer review

- Inclusion in PubMed and all major indexing services

- Maximum visibility for your research

Submit your manuscript at www.biomedcentral.com/submit
Biomed Central 